\title{
LA ERUPCIÓN DEL VOLCÁN CHAITÉN: VOYERISMO, DESCONFIANZA, ACADEMIA Y ESTADO. CONSECUENCIAS URBANAS Y SOCIALES EN LA COMUNIDAD ${ }^{1}$
}

\author{
The Chaitén volcano eruption: voyeurism, distrust, academy and State. Urban and social \\ repercussions in the community \\ Fernando Mandujano* \\ Juan Carlos Rodríguez ${ }^{* *}$ \\ Sonia E. Reyes*** \\ Patricio Medina****
}

\begin{abstract}
RESUMEN
En este artículo se presenta una descripción y análisis de una doble catástrofe: la inicial, provocada el año 2008 por la erupción del volcán Chaitén sobre el centro urbano homónimo y, seguidamente, la generada a partir de las decisiones políticas y técnicas de mitigación del fenómeno natural, que implicaron la evacuación de la población y una drástica caída demográfica del pueblo. Se exponen las formas de difusión de la catástrofe y sus narrativas, la toma de decisiones y sus efectos, así como las racionalidades intervinientes en la propuesta de un plan maestro de relocalización de la ciudad. Se reconoce cómo

\footnotetext{
${ }^{1}$ Este trabajo es parte del proyecto Fondecyt No 1120795 "Etnografía de la colonización y recolonización de Chiloé Continental. Actores, intercambios y conflictos".

* Facultad de Educación, Universidad de Playa Ancha. Valparaíso, Chile. Correo electrónico: fmandujan@yahoo.es

** Facultad de Arquitectura, Universidad de Valparaíso. Valparaíso, Chile. Correo electrónico: juancarlosrodriguezt@yahoo.com

*** Instituto de Sociología, Universidad de Valparaíso. Valparaíso, Chile. Correo electrónico: sonia.reyes@uv.cl **** Escuela de Psicología, Pontificia Universidad Católica de Valparaíso. Valparaíso, Chile. Correo electrónico: pmedinahernandez@yahoo.es
}

Artículo recibido el 27 de mayo de 2014. Aceptado el 9 de marzo de 2015. 
algunos actores locales, con posiciones ventajosas desde el punto de vista de sus inversiones, hicieron prevalecer sus subjetividades en desmedro de la propuesta encargada por el Estado para el desarrollo de un plan integral, en lo que constituye el puerto de entrada hacia la Patagonia. Metodológicamente, se implementó la estrategia del estudio de caso y recolectó información de terreno en forma multisituada entre octubre del 2012 y marzo 2013, sumado a la de publicaciones, documentos, periódicos y bases de datos secundarios.

Palabras clave: Chaitén, catástrofe, territorialización, relocalización.

\begin{abstract}
This article presents a description and analysis of a twofold catastrophe: in the first place, the Chaitén volcano eruption over the homonymous urban center, and secondly, the social drama, that was produced for the political and technical decisions for the tragedy mitigation. This provoked the town evacuation and a drastic population decline. The forms of diffusion of the disaster and its narratives, the decision making and its effects, and the rationalities involved in the proposed relocation of a master plan of the city, are present. Also it recognizes how some protagonists, with financial advantage, imposed their subjectivities, in detriment of the State proposal, for the comprehensive development plan, in what is the port of entry to the Patagonia. In methodological terms was used the case study strategy and the field data were collected in multisituada form, between october 2012 and march 2013. Also were investigated several publications, documents, newspapers and secondary databases.
\end{abstract}

Keywords: Chaitén, catastrophe, territorialization, relocation.

\title{
INTRODUCCIÓN
}

En la madrugada del día dos de mayo de 2008, el volcán Chaitén, ubicado en la provincia de Palena, en la Patagonia chilena, después de miles de años inactivo (Lara, 2009: 126) y tras una oleada de temblores inició la actividad eruptiva, siendo la mayor de su tipo registrada desde el año 1912 en Alaska (Carn et al., 2009: 205). Su columna de gases y cenizas alcanzó más de 25 kilómetros de altura (NASA, 2008), extendiéndose a la costa atlántica y cubriendo con cenizas parques nacionales y localidades pobladas de Chile y Argentina, incluyendo algunos días incluso a Buenos Aires. De todas ellas, la más afectada fue Chaitén, ubicada a sus pies y que corresponde al segundo centro poblado en importancia de la provincia de Palena ${ }^{2}$ y cuyos 4.625 habitantes urbanos fueron evacuados (De la Barrera, 2011: 82).

\footnotetext{
${ }^{2}$ El otro centro poblado importante es la comunidad de Hualaihué, paso obligado para la población chaitenina y de los alrededores a través de la combinación bimodal (mar-tierra), si hay un destino hacia Puerto Montt o viceversa.
} 
A primera hora del día se produce la evacuación por mar de mujeres, niños y personas mayores, con destino a Puerto Montt, Castro y Quellón; otros, lo hacen por sus propios medios por vía terrestre, a localidades del interior como Futaleufú y Palena, o con destino a Coyhaique. En la noche quedan menos de 1.000 personas, reanudándose al día siguiente la evacuación del resto de los habitantes. La nube llega a Futaleufú el día 4 de mayo, y el día 5 más de la mitad de la población es evacuada vía Argentina, hasta Osorno. El día 6, Chaitén es abandonada por personal técnico y militar, asentando su base de operaciones en la isla Los Desertores; Futaleufú también queda desierta.

A diez días de esa evacuación, definida como exitosa por las autoridades y organismos competentes, producto de las intensas lluvias de otoño y la acumulación de cenizas y sedimentos, se desbordó el río Blanco que cruza por el medio del centro poblado. Este, modifica su cauce de tal manera, que arrasó con gran parte de las casas, calles e infraestructuras; lo propio ocurrió con el borde costero, el que se desplazó unos quinientos metros hacia el océano, embancando el embarcadero de los transbordadores y la caleta de pescadores, producto de la gran cantidad de material volcánico y urbano arrastrado hacia el mar. Pablo Allard estima que unos 3 kilómetros cúbicos de cenizas se habrían diseminado (poloc.org/conversista/ archives/128).

Detrás de las impresionantes imágenes y noticias del desastre que recorrieron titulares de la prensa mundial de ese año, poniendo en la agenda nombres y lugares tan lejanos como desconocidos, se desencadenó un complejo proceso de decisiones, intervenciones y hechos que tuvieron el carácter de urgentes, cuyos impactos urbanos y migratorios afectaron y afectarán durante muchos años a la localidad y la zona. En este sentido, coincidimos con los términos de Edgar Gaytán (2010), quien señala que "la toma inadecuada y apresurada de decisiones por parte del Estado conlleva a nuevas acciones desastrosas y desorganizadas", a diferencia de los efectos inmediatos, los de largo plazo, son difíciles de corregir.

En este caso, la toma de decisiones afecta primero, a la localidad que es la puerta de entrada para la Patagonia, el lugar donde se inicia la conectividad terrestre para dar continuidad al territorio nacional; y, segundo, a la demografía, uno de los puntos más sensibles de la Patagonia, ya que involucra a varias generaciones de colonos, políticas de colonización fracasadas y procesos migratorios extrarregionales.

La catástrofe, entendida como la ocurrencia de un hecho extremo e impredecible que combina elementos naturales (y/o tecnológicos) y una población vulnerable, que provoca un desequilibrio en la vida cotidiana y la destrucción de sus sistemas de organización (López, 1999; Oliver-Smith, 1995), fue gestionada por el Estado de modo que salvó la vida de todos los afectados, los cuales pudieron salir adelante con sus proyectos de vida, aun cuando el proceso dejó enormes costos para la Provincia de Palena. En el escenario más inmediato, se encuentra lo que 
podemos denominar el urbano demográfico, justamente uno de los aspectos más críticos de la zona y también en el resto de las provincias y regiones de la Patagonia. El pueblo más importante para la conectividad provincial, donde se inicia la red de caminos hacia el interior fronterizo y Aysén, se despobló de la mayor parte de los habitantes, lo que tiene un impacto multi-sistémico desde el punto de vista de las posibilidades de desarrollo, arraigo, agenciamiento del Estado, decisiones de inversión, calidad de vida y territorialización.

Lo sucedido post desastre tiene gran importancia ya que constituye una fuente de interrogantes y reflexión sobre diversos aspectos propios de organismos encargados de la gestión de emergencias como de instituciones del Estado, académicas y el mundo profesional: 1) Es una experiencia de gestión de un desastre, 2) Un proceso social crítico que permite estudiar fenómenos normalmente menos visibles como la conducta de diversos actores e instituciones, 3) Un hito histórico, paradigmático y fuente de aprendizaje respecto de la certeza y validación de las decisiones, 4) Un impacto en la economía de la zona, 5) una prueba en la definición territorial y urbana de la Patagonia, 6) Un desafío para la capacidad de las universidades y centros de estudio para dar cuenta de la complejidad de las experiencias involucradas, y 7) La posibilidad de evaluar el impacto de las resolusiones a lo largo del proceso. Estas interrogantes y reflexiones, sumadas a elementos de contexto, pueden ser útiles para establecer observaciones y conclusiones que podrían ayudar a mitigar o prevenir errores o impactos futuros frente a catástrofes, inclusive redefiniendo la institucionalidad política, administrativa y técnica, en un país que convive frecuentemente con fenómenos naturales intensos y sus consecuentes desastres sociales.

Planteado así el proceso, también mirado a la distancia, observaremos que todas las decisiones afectan el espacio habitado, vivido y construido históricamente y que la localidad de Chaitén, lejos de ser una abstracción o solo un punto en el mapa, remite a una organización, apropiación y construcción social particular en la que se concreta una formación social. La existencia de Chaitén es el resultado de los procesos de sedimentación de relaciones, estructuraciones, diferenciaciones, desigualdades y conflictos propios de un Chile interior no reconocido por el centralismo capitalino y producto de la falta de ordenamiento territorial tanto para las grandes ciudades como para los poblados rurales. En este sentido, los sujetos de acuerdo a sus actividades (leñadores, pescadores, ganaderos, algueras, comerciantes del rubro hotelería y alimentario, y funcionarios del poder local y del Estado) y posiciones son productores del territorio, y estas establecen los límites de sus posibilidades y las capacidades de imaginación para concebirlo. Así, la territorialidad corresponde a la relación, el dominio y la apropiación del territorio por distintas racionalidades que afectan su representación, su organización, la forma de resolver las vicisitudes cotidianas y las relaciones de poder que le configuran. 
Conforme esto, revisaremos que en Chaitén, antes de la erupción y durante todo el proceso de reasentamiento, se revelan las posiciones objetivas y subjetivas de sus actores y el mayor control que algunos de ellos tienen de bienes y servicios que permiten marcar este territorio y la dinámica de la vida urbana. Así, resaltaremos que existe una distinta capacidad para realizar los propios intereses, estrategias y proyectos, lo que se traduce en una distribución desigual de las posibilidades de aceptación de la propuesta urbana del Estado para el reasentamiento.

De acuerdo a lo señalado, en este trabajo se presentan cinco planos que dan forma y estructura temporal al proceso de la catástrofe natural y social de Chaitén, cuyo análisis constituye su objetivo: a) El fenómeno natural mediatizado por los expertos científicos, b) La presencia mediática nacional e internacional, c) Las acciones políticas, d) La población, y e) La acción académica. En particular, nos interesa esta última, porque tenemos la convicción que se deben restituir los vínculos entre el saber y hacer, generados en la academia para el Estado, y entre la universidad pública y la comunidad a través de este.

\section{METODOLOGÍA}

Según Oliver-Smith (1999: 24) un desastre se caracteriza porque obliga a quienes lo enfrentan a actuar apremiados por el tiempo, bajo mucha incertidumbre, en un escenario natural y sociocultural complejo. La idea de estudiar este tipo de fenómenos apunta a esa incertidumbre que, inequívocamente, es un factor crítico y transversal. Como objeto de estudio, la investigación de la conducta en una catástrofe no es tan distinto de otros estudios, salvo el contexto en que se realiza (Stalling, 2007: 55), aunque agrega que la diferencia se expresa en tres aspectos esenciales: el tiempo, que subordina la recogida de datos al inicio del proceso; segundo, el acceso a datos de campo (informantes, documentos) y, tercero, la posibilidad de generalizar, es decir, obtener conclusiones válidas para estudios de desastres.

En este caso, esos aspectos tienen efectivamente un comportamiento peculiar; respecto del primero, el proceso se inicia con la sorpresiva erupción del volcán en la madrugada del día señalado, pero su actividad se mantuvo con distintos grados de magnitud durante los dos años siguientes y solo se reduce a una relativa normalidad en junio de 2011, de acuerdo a la calificación de los expertos $\left(\right.$ OVDAS-SERNAGEOMIN) ${ }^{3}$.

\footnotetext{
${ }^{3}$ OVDAS, Observatorio Volcanológico de Los Andes del Sur. SERNAGEOMIN, Servicio Nacional de Geología y Minería.
} 
En relación al segundo, el acceso a los datos, documentos y personas que proporcionen información, la situación es ventajosa respecto de aquella centrada en el pueblo, pero es escasa la relativa a las familias que, evacuadas mayoritariamente, se dispersaron sin regresar ${ }^{4}$, dificultad que -como vemos- experimentaron directamente las instituciones y profesionales que trataron de hacer seguimiento para lo que llamaremos "la solución final". Dado el tiempo transcurrido, el aporte de la difusión alcanzada por los medios de prensa, en Internet la gran mayoría, varias reflexiones académicas de por medio y la posibilidad de entrevistar a chaiteninos afectados y profesionales involucrados, facilitan notoriamente el acceso a nuevos datos, principalmente registrados en el 2012 y 2013.

Y, respecto al tercero, además de ser fuente de drama y dolor, el objeto de estudio constituye una experiencia crucial o un experimento natural (Diamond y Robinson, 2010) que independientemente de su relevancia como catástrofe, debe ser estudiada para conocer y ayudar a prevenir o mitigar otras de similares características, ya que es un escenario de conductas sociales sometidas a condiciones difíciles de observar en situaciones normales, por lo que pueden contribuir a probar o desarrollar hipótesis elusivas en situaciones normales.

En ese contexto, de gran diversidad de hechos, actores, decisiones y procesos, para recoger información de múltiples fuentes y lograr una perspectiva holística, se usó el método del estudio de caso con entrevistas en lugares dispersos (Clifford, 1997). El trabajo de terreno se llevó a cabo en tres visitas: dos durante los meses de octubre y diciembre de 2012 y otra en marzo de 2013; abarcando recorridos por la región de Los Lagos y las provincias de Palena, Coyhaique, Aysén y General Carrera. Paralelamente se elaboró un archivo de prensa, con el abundante material publicado desde el año 2008, a ello se sumaron artículos e informes originados con la catástrofe y su gestión, documentos y bases de datos públicos, que se unieron a las transcripciones de las entrevistas a informantes clave en diferentes lugares y material fotográfico recabado.

Para la validación se cruzó la diversidad de fuentes, pero en especial, se procuró la cristalización de la información que da cuenta de la complejidad del objeto de estudio, a través del análisis iterativo y cíclico (Fetterman, 2010: 112). Para ello se usaron cinco categorías claves de análisis: el fenómeno natural mediatizado por los expertos científicos, la presencia mediática, las acciones políticas, la experiencia de la población del pueblo de Chaitén y, lo que podemos denominar, la acción académica. El procesamiento y análisis fue facilitado con el programa Atlas.Ti.

\footnotetext{
4 Según informaciones proporcionadas por profesionales del Departamento de Desarrollo Comunitario del municipio de Chaitén, en diciembre de 2012, fueron múltiples las localidades que acogieron a los desplazados y más de un 70\% de la población urbana no regresó.
} 


\section{CHAITÉN Y LA PATAGONIA OCCIDENTAL}

Aunque para algunos autores la Patagonia chilena se extiende desde el paralelo 39 (Fantini, 2007:13; Said, 2011:15), la opción mayoritaria reconoce su límite norte con el Seno del Reloncaví. Sin incluir la Isla Grande de Chiloé, abarca $265.276 \mathrm{~km} 2$ desde la Comuna de Hualaihué hasta la Tierra del Fuego. A diferencia del lado argentino, donde predominan la pampa y las llanuras esteparias, el lado occidental es montañoso, accidentado y más boscoso. Incluye una parte de la Región de Los Lagos, toda la de Aysén y Magallanes (sin considerar la Antártida). Su difícil geografía está asociada con su poblamiento ancestralmente mucho menor y más tardío que el lado oriental, definida como un lugar más lejano, hostil y difícil, y con rasgos de identidad territorial más autónomos.

Palena, es la más septentrional de las ocho provincias que abarca la X región, pero también es la menos poblada de sus alrededores (con una densidad de 0,9 hab/km2; las provincias limítrofes: Llanquihue 24,4, Chiloé 18,1, Aysén 2,3 y Coyhaique 4,6) (INE 2012). Es muy lluviosa y fría, con un paisaje de densos bosques, montañosa, atravesada por ríos torrentosos y lagos encajonados. Fue tan tardía y difícilmente colonizada con incursiones desde Chiloé y desde territorio argentino, que el explorador de la zona Augusto Grossi, en el año 1951 llamaba a sus habitantes “esos chilenos solitarios de las selvas del norte de Aysén” (Martinic, 2005: 316).

Está conformada por las comunas de Hualaihué, Chaitén, Futaleufú y Palena y su poblamiento es tan reducido que salvo Hornopirén, capital de Hualaihué, ninguno de sus agrupamientos habitados alcanza el estatus de ciudad. De acuerdo a la nomenclatura del $\mathrm{INE}^{5}$ (5.000 o más habitantes), todas las capitales comunales por su población y actividades económicas, corresponden a la categoría de pueblos.

Chaitén es la entrada real para los que viajan por territorio chileno entre las regiones X y XI. Su localización en la costa, en el Golfo del Corcovado, fortaleció su condición de punto clave también para la provincia de Palena, en relación a las localidades fronterizas de Futaeufú y Palena, ya que ahí inicia la conectividad vial. La comuna de Chaitén es la más extensa $\left(8.471 \mathrm{~km}^{2}\right)$ de las cuatro de la provincia, su población estaba constituida en porcentajes similares por empleados del Estado, migrantes instalados a través de un procesos de colonización durante la dictadura y trabajadores libres o de las salmoneras, más recientemente. Su ocupación data de $1921^{6}$.

\footnotetext{
${ }^{5}$ Instituto Nacional de Estadísticas.

${ }^{6}$ Personas mayores y descendientes de los pioneros, cuentan que en los años 30 llegar desde Futaleufú a Chaitén demoraba unos 45 días. El tránsito con los animales se realizaba a través de la selva y había que "preparar picadas", es decir, abrir caminos a machetes, lo que era peligroso por los derrumbes y las crecidas de ríos y lagos. Hacia el interior, Futaleufú y Palena recién tuvieron Municipalidad en 1971, y hasta comienzos de los años 60, Chaitén seguía sin agua potable, sin luz eléctrica y sin muelle.
} 
En términos terrestres es la puerta de entrada a la Patagonia. Sin embargo, entrar o salir de ella obliga a una combinación de medios de transporte que es conocida como bi-modal, es decir, una fórmula implementada en 2010 para conectar "con Chile" a los habitantes de la provincia de Palena y los de la Región de Aysén. Incluye tres tramos marítimos y cuatro terrestres, con una frecuencia diaria durante todo el año. Un bus sale desde Puerto Montt a las 7.00 AM y debe llegar a las 18:00 horas a Chaitén, y su regreso es saliendo al medio día con un arribo a las 23:00 PM. Sin embargo, esto es una cuestión meramente formal, ya que se depende de las condiciones climáticas y de la disponibilidad de barcaza, la que a veces falla por problemas mecánicos o climáticos. De no utilizar esta modalidad, el viaje obligado -como generalmente ocurre desde los poblados del interior- es vía Argentina, lo que significa un trayecto hasta el paso Puyehue, en Osorno, y una dependencia y disponibilidad de los servicios de nuestros vecinos.

Lo que se señala no constituye un hecho menor. Más bien, habla de la existencia de un Chile interior, más binacional que longitudinal, altamente dependiente, de escasa movilidad para su población, porque un viaje de ida y regreso puede significar unos 5 días; de servicios e institucionalidad restringida, de pocas oportunidades como las brindadas por las economías de escala. Pero, se debe reconocer que es solo a partir de la construcción de la Carretera Austral a finales de los ańos 70, que es alcanzable por tierra, experimentando los mayores cambios y consolidando a Chaitén como entrada y nodo articulador de la red vial de la zona. Antes de la erupción volcánica de 2008, Chaitén era el poblado más grande en más de 130 kilómetros a la redonda, puesto que los caminos de la Patagonia no son lineales y significan mayores tiempos y riesgos que en otras partes. De modo que, la erupción del volcán Chaitén tiene como componente social a sus espaldas, la figura de un fuerte aislamiento y grandes restricciones en los planos educativos, sanitarios, alimentarios, recreacionales, laborales y económicos.

\section{La precariedad y desequilibrio demográfico de la provincia de Palena y la Patagonia en general}

En una distancia de más de $1.300 \mathrm{~km}$ y de más de $2.500 \mathrm{~km}$ en rutas, que deben combinarse con carreteras de Argentina, en la Patagonia chilena solo hay tres grandes centros urbanos: las ciudades de Coyhaique y Aysén (separadas entre sí por menos de $70 \mathrm{~km}$ ), a unos $500 \mathrm{~km}$ lineales desde Puerto Montt y a $840 \mathrm{~km}$ más al sur, la ciudad de Punta Arenas (también en línea recta). Estas son las únicas ciudades con mercados significativos, servicios públicos de importancia como hospitales, tribunales, universidades y aeropuertos funcionando todo el año. Con una superficie casi un 30\% mayor, desde el punto de vista del desarrollo urbano, esta zona es bastante más pobre y desolada que el Norte Grande. 
Con menos de un habitante por $\mathrm{km}^{2}$, la Patagonia es la zona del país con menor densidad y el censo 2012 demuestra eso; acompañada de un bajo crecimiento, pues sus tres regiones se encuentran dentro de las seis con más bajo crecimiento intercensal; pero también las mismas cifras muestran algo que es observable al recorrerla: una tendencia al despoblamiento de las zonas rurales. A lo largo de decenas de kilómetros se observan casas sin humo en sus chimeneas, sin moradores, sin animales, a la vez se aprecia la aparición de poblaciones que emergen con mínima dotación urbana en las afueras de Coyhaique y Aysén, rasgos frecuentes en un crecimiento no planificado.

Según información poblacional del INE (2012), de las cuatro comunas de la Provincia de Palena (Chaitén, 3.336 hab. urbano rurales; Futaleufú, 2.290; Hualaihué, 8.702; y Palena, 1.810), se destaca que Hualaihué es la única que tiene un crecimiento poblacional persistente y regular, justamente por su proximidad y su mayor accesibilidad a Puerto Montt y el boom de la salmonicultura en las décadas pasadas, cuyo auge y crisis se reflejan en el despliegue urbano informal de Hornopirén. Tanto por la cercanía a esa ciudad, como por la falta de conexión por tierra con el resto de la provincia de Palena, su presencia no tiene mayor impacto en el espacio provincial. Ello, sumado a la baja magnitud demográfica del resto de las comunas, convierte la pérdida de población de Chaitén en el hecho demográfico más relevante del período intercensal, ya que el leve aumento de la población en Futaleufú -en unas 200 personas- se explica por el despoblamiento de Chaitén.

\section{La definición del fenómeno natural según los expertos}

El primer informe técnico de SERNAGEOMIN (3 de mayo de 2008) decreta Alerta Roja, identifica al pequeño volcán Chaitén y no al Michinmahuida, más grande y a pocos kilómetros, como causante de la erupción. Recomienda la evacuación de toda la población y agrega: "la evolución de la erupción es de difícil pronóstico, pudiendo continuar por días, semanas o meses (o ańos)".

Efectivamente ocurre el peor escenario: La actividad del volcán se mantuvo en distintas magnitudes durante el primer ańo y en febrero del ańo siguiente, el 2009, colapsa la estructura central del cráter y se comunica: "Ninguna persona debe permanecer en la ciudad de Chaitén”, por lo que se mantiene la Alerta Roja. Al tercer ańo, en junio de 2010, SERNAGEOMIN baja el nivel de riesgo y decreta Alerta Amarilla, pero indica: "Dada la gran dimensión del domo, continúa latente el peligro de colapsos, eventuales explosiones y generación de flujos de bloques y ceniza, los cuales podrían afectar los valles adyacentes al volcán Chaitén" (El Mercurio, 2 de junio 2010).

Los adjetivos que emplean los expertos para definir la situación de la localidad son inequívocos: destruida, devastada, arrasada. Un geofísico de la Universidad 
de Tarapacá afirmó que "es imposible volver a vivir en Chaitén" (La Tercera, 21 de febrero de 2009) y expertos de la PUC declaran "inviable la reconstrucción de Chaitén" (Alfaro et al., 2010: 3). En junio de 2012, la autoridad regional del Ministerio de Vivienda y Urbanismo afirma:

...Chaitén completo es un territorio vulnerable frente a peligros naturales, por lo que su ocupación siempre conllevará un riesgo para las personas que lo habiten o realicen actividades en él y también se arriesga la pérdida o el serio deterioro de la infraestructura localizada ahí (Macaya, 2012: 5).

La importancia de estas afirmaciones es crucial, pues constituyeron el soporte profesional dentro del cual se van a mover las autoridades locales y nacionales para gestionar la etapa de solución de la catástrofe. De paso, sostiene un vecino: "los diputados y los senadores, sin ver lo que pasaba acá, inventaron la Ley Chaitén, sólo con las imágenes de la TV que mostraban un pueblo destruido y devastado..."

\section{La presencia mediática}

Las impresionantes imágenes de la erupción registradas in situ y satelitales $\left(\mathrm{NASA}^{7}-\mathrm{USGS}^{8}\right.$ ), recorrieron la prensa internacional, agregando notas en directo de la evacuación de las personas, el rescate de las mascotas, las condiciones de los refugiados, la destrucción de la ciudad y el abandono de sus enseres y bienes. La importancia de esta cobertura mediática y voyerismo radica en que difundió la imagen del pueblo y la zona como si se tratara de un verdadero holocausto, lo que mantuvo el tema en la agenda temática de la opinión pública y con ello presionó a las autoridades para implementar más ayuda, apoyo y subsidios. Esto confirmó la idea de la existencia de un Chile lejano y desconocido, el que se hace visible a través de la tragedia y la pantalla de la TV.

A unos meses, ya sin la columna de cenizas y para obtener provecho a la expectativa generada por las espectaculares imágenes, algunos chaiteninos retornados reafirman el voyerismo y organizan paquetes turísticos de visita al cráter y al pueblo devastado (Radio Cooperativa, 20 de enero de 2010). Paralelamente, estudiantes tesistas de la Pontificia Universidad Católica de Chile proponen transformar Chaitén "en un pueblo fantasma al estilo de Humberstone", abriéndose

\footnotetext{
${ }^{7}$ National Aeronautics and Space Administration, de Estados Unidos.

${ }^{8}$ USGS, United States Geological Survey.

${ }^{9}$ Antigua Oficina salitrera, cercana a Iquique y declarada Monumento Nacional y Patrimonio Cultural de la Humanidad.
} 
las posibilidades de hacer camping y recorrer el lugar a través de senderos en las cenizas" (Plataforma Urbana, 26 de febrero de 2009).

La exposición mediática generó dos formas de apreciación social del fenómeno. En primer lugar, no solo fue parte de las perturbaciones que tuvieron que soportar los refugiados en la isla de Chiloé, Puerto Montt, Osorno, Futaleufú, Palena, Bariloche, Trevelin y Esquel, entre otras localidades, sino que también fue una de las formas en que vivieron la experiencia, es decir, se convirtieron en espectadores de su propio drama. En noticieros y reportajes especiales vieron el nuevo curso y volumen del río, sus casas destruidas por el peso de las cenizas, sus mascotas abandonadas y la vida en los refugios de ellos y de otros chaiteninos (Marchant, 2010: 123). En segundo lugar, al darle visibilidad a la localidad de Chaitén y sus alrededores, incluyendo el viaje al volcán homónimo, se constituyó un marco para desarrollar lo que se conoce como la "economía de la experiencia" (Pine y Gilmor,1999). Perspectiva económica y cultural que provee vivencias, experiencias educativas, aprendizajes de la diversidad natural y cultural, y posibilidades contemplativas de apreciación del paisaje, vidas pretéritas y lugares abandonados. Es decir, un marco para descubrir, despertar sensaciones y emociones detonadas por el voyerismo de la destrucción.

Esto se ve reforzado en el testimonio recogido en el año 2012 de una de las personas que nunca abandonó Chaitén, quien lo expresa de la siguiente forma:

Si antes teníamos termas, la pesca con mosca y senderos; ahora agregamos el volcán, el que se ha transformado en una visita obligada. Desde que subí a la cumbre con el documentalista Mauricio Purto, pensé que el volcán, nuestro antiguo enemigo, se puede transformar ahora en nuestro aliado, en otro atractivo.

\section{Las acciones politicas}

El gobierno de la primera administración de la Presidenta Bachelet instaló equipos de gestión directa y el mayor financiamiento por persona invertido por el Estado para mitigar los efectos de una catástrofe en Chile hasta esa fecha ${ }^{10}$, destinando alrededor de ochenta profesionales y autoridades dedicados al apoyo de la población afectada en las localidades de refugio (Aguilera 2009). Además de disponer de esos recursos materiales y profesionales, se enfatizó en el asesoramiento científico de su gestión, consultando y contratando servicios de expertos en las diversas disciplinas vinculadas al problema, tanto instituciones chilenas (SERNAGEOMIN, OVDAS, Universidades) como extranjeras (Arup, VHP-USGS ${ }^{11}$, NASA).

\footnotetext{
${ }^{10}$ Este beneficio para los damnificados solo fue superado el año 2010 en el caso de los 33 mineros atrapados en una mina en las cercanías de Copiapó.

${ }^{11}$ VHP-USGS, Volcano Hazard Program of United States Geological Survey.
} 
Se evacuó exitosamente a la población, unas 8.000 personas, de Chaitén y otras localidades como Futaleufú, sin pérdidas humanas que lamentar (DREF, 2008). Casi la mitad de las 1.820 familias evacuadas los primeros días fueron ubicadas en refugios habilitados en colegios de Puerto Montt, un 22\% en localidades de Chiloé y un 12\% en localidades alcanzables por tierra como La Junta, Palena, Villa Santa Lucía (Programa de Apoyo a Chaitén, 2008).

Escuchando a los expertos que declaran inhabitable el pueblo (La Tercera, 13 mayo de 2008), el gobierno define una acción de apoyo para las familias, que requieren más que el simple refugio o albergue inicial, un programa de apoyo continuo en un proceso de meses o años de asistencia y relocalización a las familias. En el mes de octubre, a casi seis meses del suceso, el Estado contrata a la Pontificia Universidad Católica de Chile para un estudio urbano tendiente a reconstruir o relocalizar Chaitén, llamado "Consultoría para el Desarrollo de Lineamientos Estratégicos de Reconstrucción y Relocalización”. Este estudio consiste en presentar una propuesta sobre evaluación de desarrollo, escenarios posibles y emitir recomendaciones desde la perspectiva técnica y profesional, entendiendo que la decisión final sobre qué hacer le corresponde al Estado, ya que se trata de un plan maestro con características conceptuales (poloc.org/conversista/archives/128).

El gobierno central recibe durante el primer semestre del 2009 los informes contratados y, en seguida, con los equipos profesionales del MINVU elabora el Plan Maestro para la construcción de la Nueva Chaitén, una ciudad ideal, ícono para la entrada a la Patagonia, entregándolo a la entrante administración del Presidente Piñera. Esto acontece a pocos días del cambio de gobierno, en marzo de 2010, cuando la catástrofe natural de Chaitén y sus consecuencias había perdido el foco de interés para los medios y esa atención era acaparada por el terremoto y maremoto del 27 de febrero de 2010 y el propio cambio de gobierno.

\section{La población afectada}

La evacuación de Chaitén fue el movimiento de personas civiles y medios de transporte más grande de la historia de la Patagonia. Inevitablemente, fue una experiencia extrema, que frente al temor y el estrés de la erupción y la evacuación, agregó los costos de un extrañamiento sorpresivo, que rompió abruptamente las rutinas de la vida cotidiana de personas y familias acostumbradas a la vida tranquila y sencilla de pueblo, es decir, donde se manifestaba el absoluto control físico y psicológico del espacio, en el que convergían comunidad, naturaleza, espacio y tiempo para dar forma a su desconocida historicidad.

A pesar de la asistencia económica del Estado que se tradujo para la gran mayoría de las familias en ingresos impensados (La Tercera, 14 de mayo de 2008), en una comuna que tradicionalmente tuvo ingresos medios inferiores a la región 
y al país, de un costo de vida alto, y del apoyo de asistentes sociales, sicólogos y todos los servicios públicos, durante doce o más meses, se vivieron los dramas del desarraigo, la fractura de las redes familiares y sociales, la anomia y la desadaptación del forastero (Marchant, 2010:2011; Alfaro et al., 2010). Aunque la acción de apoyo incluyó una gran diversidad de cursos de capacitación deslocalizados, créditos y apoyo técnico para facilitar el acceso a empleos o a la reconversión laboral de los jefes de familia, hubo inevitablemente un costo en la mitigación por la pérdida del terruño, la actividad directa como la desarrollada y desaparecida subcultura de los pescadores artesanales orientada al mercado interno, la comunidad de algueras y la relación con los lugares significativos donde el habitante encontró su seguridad, la validación social y un referente cultural.

La adaptación en otras localidades mejor dotadas de servicios, con más opciones de estudio para los hijos, de trabajo, diversión, conocimiento de personas y mercado, que lo que ofrecía el pequeño pueblo y la provincia antes de la catástrofe, cada día dificultaron más la urgencia del retorno de las familias. Esto fue especialmente vivido por aquellos evacuados por mar y que encontraron refugio en centros urbanos más grandes y lejanos como Puerto Montt o la Isla de Chiloé. Solo un 12\%, compuesto por familias que se refugiaron en localidades alcanzables por tierra, estuvo menos afectado por esto. Esas personas fueron las que tuvieron mayor facilidad para regresar; primero a mirar, recuperar y evaluar o, luego, decidir reinstalarse o despedirse definitivamente de su anterior vida. Entre los que optaron por reincidir en la ocupación de Chaitén, estuvieron también los llamados "rebeldes", vecinospropietarios con posiciones ventajosas en el rubro hotelería y alimentación, que representan diferencias económicas significativas respecto del resto de la población. Estos vecinos insisten muy tempranamente en la reconstrucción de Chaitén y van a resultar clave para decidir el destino final del pueblo.

Con estos vecinos-propietarios nos referimos a aquellos que a escala local pueden ser considerados como "los ricos", aunque en términos regionales y nacionales no tengan tal condición. En este caso, el tamaño de la riqueza se encuentra dado por la acumulación de oportunidades, las posibilidades de monopolización de los rubros y por la difícil incorporación de otros competidores. Estos actores, junto con los funcionarios públicos que reciben bonos por "zona extrema" y "desempeño difícil", son quienes poseen las posiciones más ventajosas en la estructura social local y serán quienes presionarán por la rehabilitación de Chaitén y se opondrán a la venta de sus propiedades.

Entre las medidas gubernamentales de ayuda a los damnificados que se implementaron, hubo dos que tuvieron una alta incidencia en la decisión de volver o no a Chaitén. La primera, el importante efecto que tuvo la ley $\mathrm{N}^{\circ} 20.385$, del 7 de octubre de 2009, que autorizó al Estado a comprar las propiedades en el pueblo al valor que tenían antes de la catástrofe, sumándose a ello que el MINVU 
creó un alto subsidio especial para la vivienda, para facilitar el acceso a una nueva, ascendente a 670 UF (Marchant, 2011:72). La segunda, que a fines de mayo de 2009, a un año de la evacuación total, según la Cuenta Pública de la Delegada Presidencial (2 de mayo de 2009) se entregaron exitosamente 1.878 subsidios para vivienda; y, al 26 de abril de 2010, plazo final establecido por el instrumento legal, el $83 \%$ de los beneficiarios con la Ley que permite vender sus propiedades al fisco, había aceptado esta opción (El Repuertero, 26 de abril de 2010).

A la luz de los informes de los expertos que declararon al pueblo como inhabitable, la compra de las casas por parte del fisco fue una fórmula que claramente permitió al Estado reforzar su decisión de no permitir el repoblamiento. Al entregarles a los vecinos un poder comprador para adquirir otra vivienda, sumado a un subsidio adicional para el mismo efecto, facilitó el proceso para que cada familia se relocalizara de acuerdo a su propia elección y así no perpetuar indefinidamente el estatus de desplazados, situación que habría sido insostenible para las personas. La recuperación de la normalidad en la vida de las víctimas, es en todos los casos de gestión de catástrofes una prioridad, por lo que se administraron soluciones para que cada familia pudiese construir por sí misma esa normalidad en un nuevo lugar.

La venta fue una decisión radical y sin vuelta atrás. Con ello el extrańamiento seńalado más arriba dejaba de ser una espera indefinida para un regreso incierto y se convertía en el rito de pasaje para un nuevo comienzo, lejos del pueblo devastado e inhabitable que fueron parte del discurso de los expertos y los medios de comunicación. Sin embargo, el que gran parte de Chaitén haya pasado a manos del Estado demostró que la actividad espacial de los actores es diferenciada, que las capacidades de crear y recrear oportunidades se distribuyeron de manera desigual y que la venta o no venta de propiedades reveló la posición social de cada uno en la localidad y en el territorio.

La decisión generó un antagonismo radical entre los llamados "cobardes", que se fueron y los "rebeldes" que no quisieron abandonar Chaitén o entre aquellos "seducidos" por el Estado y los "rebeldes" que defendieron a toda costa sus pertenencias, que no quisieron abandonarlo y reivindicaron siempre la posibilidad de habitar y recuperar el pueblo. Entonces nos señala uno de ellos, que frente a la incompletud del pueblo o a la figura desierta, ya que pareciera en 2013 y 2014 que el pueblo no tuviera centro o que su estructura no condujera a ninguna parte, que: "Hay cosas que nos tienen entrabados como la Ley Chaitén, que nos dejó entrabados a quienes queríamos seguir viviendo acá. En el sentido que de pronto el pueblo se ha convertido en un pueblo fiscal".

Conforme a lo señalado, las adjetivaciones polares revelan una nueva ocupación y segregación de los espacios por parte de propietarios y ocupantes ilegales, una distinta geografía del poder y una nueva agenda de desarrollo local. 
Esta responde a la creación de una territorialidad diferente que se sustenta en la solidificación de posiciones de poder y de ventaja económica, en la desigualdad, la discriminación, la exclusión y en la exacerbación de la división interna. No se trata solo de fronteras sociales, se trata también de la manifestación de las condiciones de habitabilidad que cada uno ha logrado consolidar en una economía post desastre. Ejemplo de ello es que las obras desarrolladas en infraestructura, como la habilitación de tramos de la Carretera Austral (ruta G7) y el nuevo aeródromo, han tenido como directos beneficiados económicos a los "rebeldes" quienes manejan el rubro hotelería, supermercado, ferretería y mecánico. El resto de la población, solo ha sido beneficiada con trabajos no calificados en las mismas obras. Los beneficiados además logran resolver las limitaciones locales en el ámbito de la educación y salud, con servicios en Puerto Montt, Coyhaique o Argentina, pasando la densidad demográfica a ser un problema menor; en tanto para los otros, las limitaciones se hacen más evidentes, ya que a menor población y con ventas aseguradas por los comerciantes para las empresas contratistas o tercerizadas, todo es más caro.

A "los rebeldes" que nunca abandonaron el pueblo realmente, durante 2011 se les suman unas 160 familias que se toman las casas de la "zona prohibida", el sur de Chaitén. Y recién, en febrero de 2013, el Ministerio de Bienes Nacionales puso a la venta 112 inmuebles, entregándoles la primera opción de compra a sus anteriores propietarios. También ha arrendado alrededor de 70 propiedades a particulares y entregado 49 concesiones y destinaciones para el funcionamiento de diversos servicios públicos, gran parte de ellos que regresan: Municipalidad de Chaitén, Registro Civil, Ministerio de Bienes Nacionales, Gobernación, Ministerio de Educación, Ministerio Público, Aduana, Conaf, Servicio de Salud, SAG, Indap e INP.

\section{La acción académica}

La gestión de la catástrofe de Chaitén contó con el acierto de poner a disposición de la comunidad académica la tarea de contribuir a su estudio y explorar las soluciones posibles. El liderazgo lo impuso el convenio del gobierno con la Pontificia Universidad Católica de Chile (octubre de 2008) la cual, en un consorcio con la Universidad Austral, Arup (una consultora de primer nivel mundial) y el Observatorio de Ciudades PUC, realizó un trabajo que fija un hito en la forma de estudiar procesos urbano-territoriales en escenarios de riesgo ambiental en Chile (Observatorio de Ciudades PUC, 2009). Este trabajo que culmina con una propuesta de relocalización en Santa Bárbara, caserío ubicado 10 kilómetros al norte, se expresa en un proyecto de ciudad modelo, en sintonía con la identidad de futuro de la Patagonia y acreditada como ciudad ecológica (Green Globe Brand certified \& benchmarked, PUC, op. cit.: 127). Se trataría de una Eco-villa, cuyos criterios principales serían: el diseño y construcción de una ciudad amigable con 
la naturaleza, bajo un enfoque sostenible e implementando diversas estrategias sustentables.

Dibujada la ciudad sobre una verdadera hoja en blanco, es decir, como una gran oportunidad, se señala en el informe: "La localidad cuenta con una geografía y paisaje diverso que es una oportunidad para desarrollar los diferentes atributos turísticos, ambientales y urbanos que permitirán enriquecer la imagen de la ciudad: vistas, quebradas, zonas de bosque maduro, costanera de playa, entre otras". El plan maestro, desarrollado con participación ciudadana, recoge los criterios de los pobladores en los más diversos ámbitos: energéticos, habitacionales, recreacionales, tecnológicos, laborales y de servicios, con el fin de dar forma a una comunidad sustentable en términos ambientales, sociales y económicos (http://www.plataformaurbana.cl/).

En abril de 2009, el Intendente regional anunció que se descarta la propuesta PUC, por el costo de los predios privados que contempla y el MINVU elabora un nuevo proyecto para la Nueva Chaitén (La Tercera, 16 de abril de 2009), asentado en la misma localidad de Santa Bárbara, pero sobre suelos fiscales. A los pocos días de asumido el gobierno del Presidente Piñera, y aun con las réplicas del terremoto y tsunami del 27/F, en marzo de 2010, el MINVU entrega El Plan Maestro Ciudad Chaitén (División de Desarrollo Urbano-MINVU, 2010). El informe propone "una ciudad con una fuerte identidad paisajística y cultural, que incorpore criterios de sustentabilidad ambiental, social y económica, que garantice una alta calidad de vida para sus habitantes, y que se consolide como la puerta de acceso a la Carretera Austral".

En mayo, el nuevo gobierno confirma la construcción en Santa Bárbara (La Nación, 27 de mayo de 2010) y, transcurrido casi un año después, en abril de 2011, cambia de decisión y anuncia la reconstrucción de Chaitén en el sector norte del mismo pueblo, en lo que denomina "Plan Solución Chaitén". Con ello se abandonan las propuestas de la PUC y del MINVU y se impone la propuesta de los chaiteninos "rebeldes", es decir, la reconstrucción en el mismo emplazamiento.

\section{La recolonización de Chaitén o las confianzas rotas}

Pese al gran esfuerzo realizado, primero por las universidades y luego por los profesionales de la División de Desarrollo Urbano del MINVU, el proyecto de relocalización en Santa Bárbara no prosperó. Todo indica que no logró algún nivel de arraigo, ni despertó confianzas en las expectativas de los habitantes, probablemente por lo que seńala Baeza (2010:60-61): la poca credibilidad en los aparatos del Estado y en la información proveniente del mismo. Ni en los que vivieron los primeros meses del extrańamiento o refugio con la esperanza de volver, ni en aquellos "rebeldes" que se negaron a abandonar el pueblo hubo confianza. El indicador más claro de ello es la absoluta ausencia de alguna manifestación de protesta o reclamo por su descarte definitivo. 
Después de haber visto imágenes de una eco-villa que llevaban prácticamente a Noruega, a casas soñadas, invernaderos sorprendentes, una marina, escuelas inimaginables, torres eólicas, pasarelas de madera, entre muchas más, señala un vecino:

A lo mejor pudo haber sido una buena idea lo de la Nueva Chaitén... lo que pasa es que la experiencia en Chile muestra que se hacen puentes que se caen después que los arman y después los que quieren botar no se caen, que hacen trenes que nunca llegan a Puerto Montt; que hacen hospitales sin camas; que hacen hospitales sin acceso... Entonces ¿̇cuál era la posibilidad de que aquí surgiera algo bueno? Además, tomando en cuenta que nadie lo estaba pidiendo. Porque aquí no hubo un clamor de parte de los chaiteninos pidiendo: ¡hágannos una nueva Chaitén!

Otro agrega: "Tenemos que estar en nuestro pueblo porque si no estamos lo hacen desaparecer"; Una mujer de 55 años refuerza lo señalado a modo de interrogación: “¿Cómo confiar que a los chaiteninos, que siempre han estado abandonados por la historia, les van a hacer una ciudad de lujo?"

En paralelo a esta apreciación, hubo algo que siempre hizo ruido o despertó sospechas entre algunos de los habitantes: ¿Por qué tanto interés en comprar tan rápidamente los sitios y viviendas destruidas por parte del Estado y a valores que presentaban conformidad para los habitantes? ¿Era una motivación del Estado o una presión urgente de las empresas mineras o energéticas? ${ }^{12}$ No se trata de dar crédito a esta afirmación, pero desde la antropología, lo real, también se construye desde el rumor o desde lo no sabido. Por ello, tres elementos aparecen en los registros de campo, como fuentes de duda y de alerta para la gente, lo que se transforma en una dificultad cartográfica para situar la información, litigando con lo "políticamente correcto", es decir, la evacuación, relocalización y protección de las personas. En primer lugar, se instala la idea de que en el sector sur de Chaitén, existiría una mina de oro y de plata, por lo que el Estado le transferiría los terrenos a privados. En segundo lugar, el despeje de la ciudad destruida, facilitaría el trabajo expedito y sin oposición para la carretera eléctrica que vendría desde el proyecto HidroAysén. En tercer lugar, algunos sostienen que se envían muestras de agua hacia Europa, con fines de que estas sean analizadas para cuando el recurso para consumo humano escasee en las próximas décadas. Es decir, tenemos un rumor o varios rumores sobre lo que acontece no sólo en Chaitén sino en la Patagonia, lo que también coadyuvó a debilitar la propuesta.

Por cierto, la población residente y los funcionarios del municipio o de la Gobernación Provincial no cuentan con información técnica para avalar alguna de estas sospechas sobre el apremio por comprar y despejar lo inhabitable, lo que

\footnotetext{
${ }^{12}$ Registro de campo, octubre de 2012.
} 
desde su inconsistencia constituye cognitivamente un territorio sin mapa. Pero, lo indudable, es que estos aspectos, sumados a lo que aprecian como una ruta G7 sobredimensionada (ancho de la vía), los nuevos puentes (también mayores en tamaños) y una importante pista aérea, desdibujan la aceptación de las contrapartes técnicas, políticas y las propuestas profesionales y mantienen la imagen consolidada de un Estado casi ajeno al up down cultural e identitario que refleja su propia historia.

Los denominados "rebeldes" tuvieron un rol clave en la "solución final". Desde los primeros días de la evacuación en que el gobierno se vio obligado a solicitar autorización ante los tribunales de justicia para obligarles a abandonar el pueblo, estos discreparon de los diagnósticos oficiales, que dieron por destruida la localidad, y destacaron que el sector norte permaneció "muy poco afectado", siendo "habitable", incluso después de las peores salidas del río. Un diagnóstico casi textual, va a usar la administración del presidente Piñera dos años después, cuando anuncia la reconstrucción en su lugar original.

\section{DISCUSIÓN Y CONCLUSIONES}

Entre los factores que pueden contribuir a explicar el por qué no se construyó una nueva ciudad, lo que es una derrota para el mundo académico y su pretensión de hacer contribuciones serias a la comunidad y al Estado, donde se diluyeron todas las propuestas técnicas y profesionales de avanzar a centros poblados sostenibles y sustentables, capaces de retener a la población, Macaya (2012:6) menciona dos: La presión de los "rebeldes" y el costo de construir y habilitar la ciudad modelo Nueva Chaitén en Santa Bárbara. A ellos podemos agregar dos factores más: El cambio de prioridades del gobierno entrante y un efecto disfuncional o paradójico del programa de apoyo a las familias, el que se tradujo en ayuda "para adaptarse lejos" (el estatus de refugiado indefinido era insostenible, como se ha seńalado). De este modo, el vivir separados luego de la evacuación, de manera dispersa entre vecinos y familiares, contribuyó a cortar lazos sociales, afectivos y territoriales. Esto último, constituiría el gran costo social o segunda catástrofe: la ruptura del tejido social. Esto afecta no sólo a vecinos, sino también familias, lo que es reafirmado muy claramente por una joven avecindada en Futaleufú: "Mis padres se quedaron viviendo en Puerto Montt porque allí hay hospital y mis hermanos mayores se quedaron viviendo en Castro, en la isla de Chiloé, yo me quedé aquí porque como no tengo estudios no tengo posibilidades en las grandes ciudades"13.

La acción de los "rebeldes" se consolidó como un discurso que terminó por imponerse, debilitando la oferta académica de una "Nueva Chaitén" como

\footnotetext{
${ }^{13}$ Registro de campo, octubre de 2012.
} 
confluencia natural de rutas de transporte, lugar de descanso, de interés turístico y de abastecimiento de combustible. A diferencia de los expertos, cuyos diagnósticos eran solo declaraciones, esos vecinos, insistiendo en vivir en el lugar destruido y defendiendo su derecho a hacerlo, terminaron por legitimar, con su propio ejemplo, su diagnóstico de "Chaitén habitable". Su opción tenía otros atributos, que quizás resultaron más concordantes con el imaginario de la gente de la Patagonia: no rendirse ante la adversidad, no abandonar ni traicionar el lugar y la casa que los vio formar su familia, vencer a la naturaleza como lo hicieron siempre los colonos.

La fragmentación comunitaria no solo propició a la larga el debilitamiento de la cohesión, las organizaciones locales y el apego con Chaitén, asociable al bajo nivel de retorno observado, ya que en la actualidad no habitan más de 1.300 personas o menos de 300 familias $^{14}$. Pero, también esa dispersión, debe haber dificultado crecientemente la validez de diversas encuestas y dinámicas para estudiar las expectativas de estas personas respecto del proyecto Nueva Chaitén y a la vez, es uno de los factores que dificultó el desarrollo de un discurso compartido para la solución que se adoptó finalmente.

Las facilidades para reinsertarse en las nuevas localidades propiciadas por el Programa de Apoyo a las Familias, se ve acentuada no solo por la compra por parte del fisco de la vivienda abandonada en la evacuación, sino adicionalmente con el subsidio preferencial para la compra de otra. También consolidan la dispersión otras iniciativas como las becas y cupos para estudio de los hijos, programas de capacitación, reconversión laboral y terapia psicológica. Es decir, facilidades que con el paso de los meses hicieron cada vez más viable y atractivo recomenzar la vida en los lugares de acogida, provocando un delta entre nińos y adultos, y entre Chaitén y la nueva residencia, consolidando para muchos la diáspora que comenzó con la catástrofe. En cambio, frente a estas facilidades para adaptarse a sus nuevos lugares de vida, las que también deben ser leídas como oportunidades, la ciudad de Chaitén se empezó a percibir de manera más intensa como precaria y su condición de habitable fue siempre "una completa incertidumbre" (González, 2011:119), ya que nunca estuvo claro si se podía volver a la misma, ni cuándo, así como tampoco hubo señales que verdaderamente se estuviera reconstruyendo la Nueva Chaitén en Santa Bárbara. En muchos de nuestros registros de campo se repite la siguiente sentencia: "todo se veía bello, pero todos sabíamos que no se podía construir en medio del mallín".

Para la nueva administración del Estado, no tenía sentido insistir en un proyecto de alto valor como la construcción de la Nueva Chaitén, estimado en 350 millones de dólares según Macaya (2012:6), pues este no contaba con un apoyo

\footnotetext{
${ }^{14}$ Datos proporcionados por el Departamento de Desarrollo Comunitario de la Municipalidad de Chaitén.
} 
claro de los potenciales beneficiarios. Eso explica que la situación a seis años, es que el pueblo se encuentra dańado y minimizado, con un cuarto de su población. No solo estamos frente a una reducción del estímulo "a la formación de la red de relaciones a partir de los intercambios aleatorios que suscita la ciudad" (Remý y Voyé, 2006: 12), ya que también es un empobrecimiento del potencial de desarrollo y calidad de vida del hinterland rural y el sistema de pueblos y localidades con los cuales intercambian servicios. El que la mayoría de las familias haya decidido no regresar cuando se les facilitó la opción de radicarse en las ciudades de refugio, dice algo respecto de lo dura que puede resultar la vida en zonas tan aisladas, en las fronteras interiores.

El aislamiento que también sufre el resto de las localidades de la provincia de Palena, es un costo para las generaciones actuales: Chaitén perdió vida, es un mercado más pequeño, hay menos ciudadanos que voten, opinen y protesten, menos niños en su escuela y en sus calles, menos fuerza de trabajo, menos público para realizar eventos, menos lectores, menos conversaciones. El aislamiento y la distancia significan un costo de la vida más alto, menos oportunidades, menor esperanza de vida. En Palena, por ejemplo, esta es diez años menos que en el resto del país, (El Mercurio, 31 de marzo de 2013). La supervivencia es un poco más difícil, las oportunidades un tanto menos equitativas, para quienes nacerán en este territorio después de la catástrofe de Chaitén, aunque no podamos cuantificarlo.

Quizás, las probabilidades de haber impedido el despoblamiento fueron muy pocas, en las condiciones que se dieron los acontecimientos, pero lejos, hubo una oportunidad para Chaitén y para la Patagonia que se perdió, así como para el mundo académico y profesional. La ciudad ecológica y modelo fue una oportunidad que estuvo muy cerca: la Nueva Chaitén era un proyecto único, con enormes proyecciones, un atractivo obligatorio para habitantes y turistas, incluso un estímulo para regresar y refundar.

Si en la Patagonia la demografía es frágil, con un crecimiento reducido que se concentra en dos o tres escenarios urbanos, mientras el aislamiento y el difícil desplazamiento es un rasgo de la mayor parte de su territorio, son justamente las comunas con aislamiento crítico las que más sufren ese despoblamiento. La catástrofe urbana y demográfica de Chaitén no deja de ser un menoscabo a la habitabilidad de la provincia y de todo el territorio, es un fortalecimiento a la condición de frontera interior, de zona apartada de Chile.

A partir de esta experiencia, también debemos destacar a modo de hipótesis y conclusión general, que la vinculación entre ciencia y política, entre academia y sociedad fue deficiente: las esferas de los expertos, los políticos y la comunidad no se sincronizaron, no crearon puentes o narraciones compartidas que hubiesen facilitado sacar provecho de las oportunidades que claramente hubo. En este sentido, solo respecto del espacio y el territorio se presentan cuatro ejes diferenciados y que 
no se articularon: el político y jurídico, controlado por el poder representado por el Estado; el de las instituciones académicas; el cultural, o simbólico-cultural, que corresponde las identificaciones e imaginarios de la comunidad; y el económico, referido a la red espacial vinculado con las actividades y prácticas económicas de quienes tenían localmente posiciones más ventajosas. Actuaron antecedentes de difícil pesquisa, especialmente sobre la estratificación local, la condición de funcionario público o no, el daño sufrido a los bienes según ubicación espacial, la edad, el género, las expectativas, los imaginarios y la mejor adaptación a lo nuevo de algunos miembros de la familia, entre otras. Estas variables nos hablan del por qué ciertas personas resistieron de distinta forma los efectos de la catástrofe y el por qué la capacidad de recuperación también se encuentre distribuida.

\section{REFERENCIAS}

Aguilera, Rodrigo. "Chaitén: El lado B de la Tragedia". Revista Nos (2009). Disponible en:<http://www.revistanos.cl/2009/02/chaiten-el-lado-b-de-latragedia/>. [Consultado el 10 de enero de 2010].

Alfaro, Valentina, Chahuán, Camila y Reyes, Carolina. "Chaitén, la comunidad fantasma de la carretera Austral. Pontificia Universidad Católica de Chile. Facultad de Ciencias Sociales”. Escuela de Trabajo Social. Desarrollo Comunitario y Ciudadanía, 2010.

Angenot, Marc. Discurso social. Los limites históricos de lo pensable y lo decible. Buenos Aires: Siglo XXI, 2010.

Baeza, Manuel Antonio. "Carnaval perverso: terremoto + tsunami y saqueos en el Chile de 2010", Sociedad Hoy 19 (2010): 53-69.

Burgos, Juan Pablo. "Lo que menos hacemos es andar preocupados del volcán”, El Ciudadano (2009): 23.

Carn, Simon, et alt., S. A., "The Unexpected Awakening of Chaitén Volcano, Chile". Eos 90/24 (2009): 205-212.

Clifford, James. Routes: Travel and Traslation in the Late Twentieth Century. Cambridge: Harvard University Press, 1997. 
Cooley, Charles. "The Theory of Transportation". A Mead Project source page. (1894). Disponible en: <http://www.brocku.ca/MeadProject/Cooley/Cooley_1894.html>. [Consultado el 15 de octubre de 2012].

Diamond, Jared y Robinson, James. Naturals Experiments of History. Boston: Harvad University Press, 2010.

División de Desarrollo Urbano - MINVU. "Plan Maestro Ciudad Chaitén. Informe Final". Disponible en: <http://www.plataformaurbana.cl/wpcontent/uploads/2010/04/1270556064_plan_chaiten_informe_final.pdf. [Consultado el 5 de octubre de 2012].

DREF. "Chile: Volcanic Eruption". Disponible en: <http://www.redhum. org/archivos/pdf/ID_2232_Redhum_CL__DREF_Operation_No._ MDRCL003_Volcanic_Eruption.pdf>. [Consultado el 15 enero 2013].

De la Barrera, Francisco, Reyes-Paecke, Sonia y Meza, Luis. "Análisis del paisaje para la evaluación ecológica rápida de alternativas de relocalización de una ciudad devastada”, Revista Chilena de Historia Natural 84/2 (2011):181-194.

Fantini, Francisco. Patagonia Chilena. Historia. Santiago de Chile: Patagonia Media, 2007.

Fetterman, David M. Ethnography. California: SAGE Publications, 2010.

Gaytán, Edgard. "Cambios en los vínculos afectivos entre difuntos y deudos en situaciones de desastre: 27/F 2010 Chile. La emergencia invisible", Sociedad Hoy 19 (2010): 87-111.

González, María José. "Estudio del Impacto Territorial - Ambiental Generado por la Erupción del Volcán Chaitén". Memoria para optar al Título de Geógrafa. Chile: Universidad de Chile, 2011.

Güss, C. Dominik. "Cultural Influences on Disaster Management: A Case Study of the Mt. Pinatubo Eruption", International Journal of Mass Emergencies and Disasters 22/2 (2004): 31-58.

INE. "Resultados Censo de Población y Vivienda 2012". Disponible en: <http:// www.ine.cl>. [Consultado el 10 abril 2013]. 
Lara, Luis E. “The 2008 Eruption Of Chaitén Volcano, Chile: A Preliminary Report," Andean Geology 36/1 (2009): 125-129.

López, Marisa. "La contribución de la Antropología al estudio de los desastres: El Caso de huracán Mitch en Honduras y Nicaragua”, YAXKIN-Instituto Hondureño de Antropología e Historia XVIII (2009): 1-14.

Macaya, Patricia. "Volcán Chaitén: Consecuencias y discusiones". Ensayo en Teoría y Política Ambiental. Santiago: Universidad de Heidelberg - UCH - PUC, 2012.

Marchant, Juan Paulo. "Lágrimas de ceniza. Estudio cualitativo sobre la experiencia de desplazamiento de los habitantes de Chaitén, asentados en las ciudades de la Isla de Chiloé y Puerto Montt”. Proyecto de Práctica Profesional: Universidad de Chile, 2010.

Marchant, Juan Paulo. Desplazamiento de Chaitén desde una perspectiva psicosocial. ¿Qué ocurrió con su población después del desastre? Leipzig: Editorial Académica Española, 2011.

Martinic, Mateo. De la Trapananda al Aysén. Una mirada reflexiva sobre el acontecer de la Región de Aysén desde la Prehistoria hasta nuestros dias. Santiago: Pehuén Editores, 2005.

Molina, J. et al. "Buscan comprar 800 hectáreas en Chaitén para reconstruir el pueblo". (2009). Disponible en: <http://www.plataformaurbana.cl/ archive/2009/02/10/buscan-comprar-800-hectareas-en-chaiten-parareconstruir-el-pueblo/>. [Consultado el 5 de enero de 2013].

NASA. "Chaitén Volcano Erupts". Earth Observatory. (2008). Disponible en: <http://earthobservatory.nasa.gov/NaturalHazards/view.php?id=19887>. [Consultado el 5 noviembre de 2012].

Observatorio de Ciudades UC. "Informe final Etapa 1". Consultoría Para El Desarrollo De Lineamientos Estratégicos De Reconstrucción / Relocalización Y Plan Maestro Conceptual Post-Desastre Chaitén. (2009). Disponible en: <http:// www.goreloslagos.cl/resources/descargas/acerca_de_gore/doc_gestion/ chaiten/1er_informe_version_final.pdf>. [Consultado el 4 de octubre de 2012]. 
Observatorio de Ciudades UC. "Informe final Etapa 2". Consultoría Para El Desarrollo De Lineamientos Estratégicos De Reconstrucción / Relocalización Y Plan Maestro Conceptual Post-Desastre Chaitén. (2009). Disponible en: http://www.goreloslagos.cl/resources/descargas/acerca_de_gore/doc_ gestion/chaiten/2do_informe_version_final.pdf>. [Consultado el 4 de octubre de 2012].

Observatorio de Ciudades UC. "Informe final Etapa 3". Consultoria Para El Desarrollo De Lineamientos Estratégicos De Reconstrucción / Relocalización Y Plan Maestro Conceptual Post-Desastre Chaitén. (2009). Disponible en: $<$ http://www.goreloslagos.cl/resources/descargas/acerca_de_gore/doc_ gestion/chaiten/3er_informe_version_final.pdf>. [Consultado el 4 de octubre de 2012].

Office of Population Research. "Hokkaido and Karafuto: Japan's Internal Frontier," Population Index 12/1 (1946): 6-13.

Oliver-Smith, Anthony. "Perspectivas antropológicas en la investigación de desastres", Desastres y sociedad 5/3 (1995): 1-21.

Piñera, Sebastián. "Piñera confirma reubicación de Chaitén en Santa Bárbara". La Nación. (2010). Disponible en: < http://www.lanacion.cl/pinera-confirmareubicacion-de- chaiten-en-santa-barbara/noticias/2010-05-27/180052. html> [Consultado el 12 de noviembre de 2012].

Piñera, Sebastián. "Piñera dio a conocer "Plan Solución Chaitén" y oficializó refundación de la ciudad". Cooperativa. (2011). Disponible en: <http://www.cooperativa. cl/noticias/pais/region-de-los-lagos/volcan-chaiten/pinera-dio-a-conocer-plansolucion-chaiten-y-oficializo-refundacion-de-la-ciudad/2011-04-09/223055. html> [Consultado el 7 de noviembre de 2012].

Remý, Jean y Voyé, Liliane. La ciudad ¿hacia una nueva definición? Zaragoza: Bassarai Ediciones, 2006.

Pine, Joseph y Gilmore, James. The Experience Economy. Boston: Harvard Business School Press, 1999.

Riffo, Luis. Chaitén Tiempos pretéritos. Santiago de Chile: LOM, 1992. 
Turnpenny, John, Jones, Mavis y Lorenzoni, Irene. "Where Now for Post-Normal Science?: A Critical Review of its Development, Definitions, and Uses", Science, Technology \& Human Values 36 (2011): 287-306.

Stallings, Robert. "Methodological Issues". In Habidán Rodríguez, Enrico Quarantelli \& Ruseell Dynes (eds.). Handbook of Disaster Research. New York: Springer (2007): 55-82.

Sernageomin. "Los flujos de lodo que afectan a Chaitén continúan extendiéndose". La Tercera. (2008). Disponible en: <http://www.latercera.com/ contenido/25_12135_9.shtml> [Consultado el 3 de febrero de 2013].

SUBDERE-PUC. Diagnóstico y propuestas para la integración de territorios aislados. Santiago: Lom, 1999.

Villa, Macarena. "Esperanza de vida es 10 años menor en las comunas de las Guaitecas, Palena y Camiña". El Mercurio. (2013). Disponible en: <http:// www.saludpublica.uchile.cl/home/images/pdf/Esperanza_de_vida_El_ Mercurio_31_marzo.pdf>. [Consultado el 31 de marzo de 2013]. 
